\title{
SmartObserver ${ }^{\circledR}$ Deployment in a Tube Forming Factory
}

\author{
Kaio Facó Studart*, Nilson Martins Vilar, Davi Nunes Oliveira \\ Universidade de Fortaleza, Av Washington Soares, 1321, Fortaleza, 60.811-905, Brazil \\ *Corresponding Author: kaiostudart@gmail.com
}

\begin{abstract}
This article will seek to demonstrate that the constant search for optimization of production processes is crucial for companies to continue increasingly profitable and competitive in the industrial market. The paper will describe the implementation process of Smartobserver ${ }^{\circledR}$ software in a Tube Forming Machine and demonstrate the gains from this deployment.

Scenarios will be presented regarding the divergences contained in manual and automatic notes, demonstrating that decision-making will be faster and more assertive as soon as the information reaches the managers.
\end{abstract}

Keywords: SmartObserver ${ }^{\circledR}$, Industry 4.0, Monitoring

\section{Introduction}

The current Brazilian scenario imposes that companies, regardless of the segment, are increasingly competitive to remain at the top. For this to happen, companies seek to reduce their costs in several ways, such as: increasing productivity, reducing process losses, good inventory management, good asset management, improved decision making, among others ${ }^{(1)}$. Adding the factors that help reduce costs to the particularities of each production process, the unit cost of the products offered by the companies is computed. This unit cost will make them competitive or not.

Most of a company's cost reduction opportunities are in productive processes, in this sense the evolution of technologies has helped to identify the root causes that lead to cost growth ${ }^{(1)}$.

The quest for efficiency in production processes has become a key factor for the development and competitiveness of companies, especially considering that we are experiencing the fourth industrial revolution ${ }^{(1)}$.

This revolution was called "Industry 4.0 " by members of the German government, with increasingly high technology linked to manufacturing processes which, will make systems more and more intelligent, enabling the ability to respond to interference more flexibly and thus enable optimized decision making ${ }^{(2)}$.

In this sense, in 2016, IFM Company launched Smartobserver ${ }^{\circledR}$ software, which aims to contribute to the increase of productivity and energy efficiency, through the continuous monitoring of the conditions of the asset, allowing the early detection of defects ${ }^{(3)}$.

In this paper it is discussed the application of Smartobserver ${ }^{\circledR}$ in a large industry in the metallurgical industry. We will observe the results on productivity, costs, speed in decision making, as well as the benefits for the maintenance sector, which from this software can monitor the variables of the online asset, eliminating the figure of the inspector, resulting in a reduction of costs and reliability of the data.

Therefore, the objective of this article is to demonstrate the gains obtained with the implantation of Smartobserver ${ }^{\circledR}$ software in a Tubing Forming Machine. The study was carried out in a company from Fortaleza - CE(Brazil), and was implemented in its equipment with higher production.

\section{SmartObserver ${ }^{\circledR}$ Implementation}

Before demonstrating the obtained results, it is necessary to describe the software implementation process. In order to facilitate the understanding, the implementation of Smartobserver ${ }^{\circledR}$ was subdivided into:

- LineRecorder;

- Communication Structure;

- Software;

- SmartObserver configuration.

\section{$2.1 \quad$ LineRecorder}

Most companies have difficulties transmitting the information contained in industrial processes to their management systems. In the company analyzed in this case, the system is SAP ${ }^{\circ}$ ERP (Enterprise Resource Planning). 
In order to solve this problem, IFM has developed LineRecorder ${ }^{\circledR}$ (LR) software, which works together with SmartObserver $\AA$. LR is a gateway software that allows bidirectional communication between sensors, PLCs and HMIs with IT systems ${ }^{(4)}$.

From LR it is possible to transmit the sensor data directly to the company software, throughout the plant or even worldwide. The real-time evaluation of the acquired database allows an increase in production efficiency under the keyword Industry 4.0.

Figure 1 presents LR function visually in the data acquisition framework that will be used for SmartObserver ${ }^{\circledR}$.

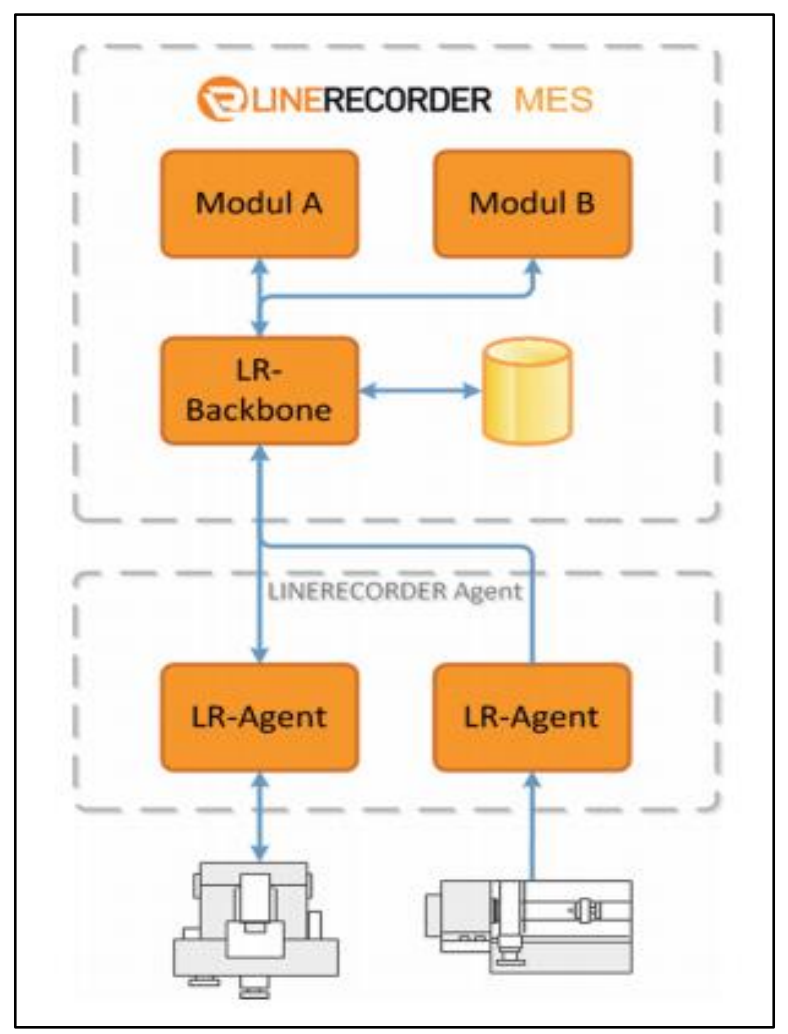

Fig. 1. LineRecorder Overview

The greatest advantage of this software is the ease of implementation, requiring only its configuration without the need to create a programming environment. During field deployment, it took only a few hours for the system to communicate with a Siemens S7-300 PLC.

This ease of deployment allows the system installation to be done in a short time. In the case of the plant under study, the setting was carried out in two days, which resulted in a low cost of project implementation.

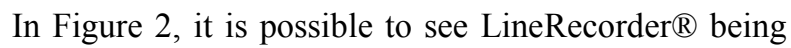
the bridge that connects the sensors and controllers of the factory floor to SmartObserver ${ }^{\circledR}$.

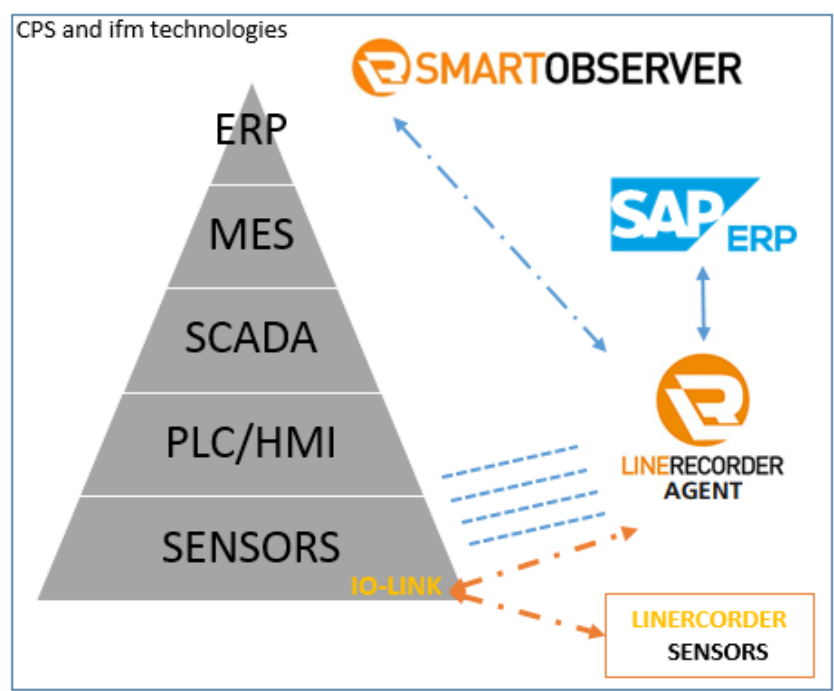

Fig. 2. Connection between IFM Technologies

\subsection{Communication Structure}

The communication between the physical and virtual environment can be done in two ways. The first is to use AT1020 module, or similar IFM, to interface PLCs, HMIs, sensors and the plant's network infrastructure. If this module is used, it is possible to use IO-Link sensors, thus, there will be an automatic recognition SmartObserver $($. In figure 3, can be visualized a complete structure exemplified by IFM (5).

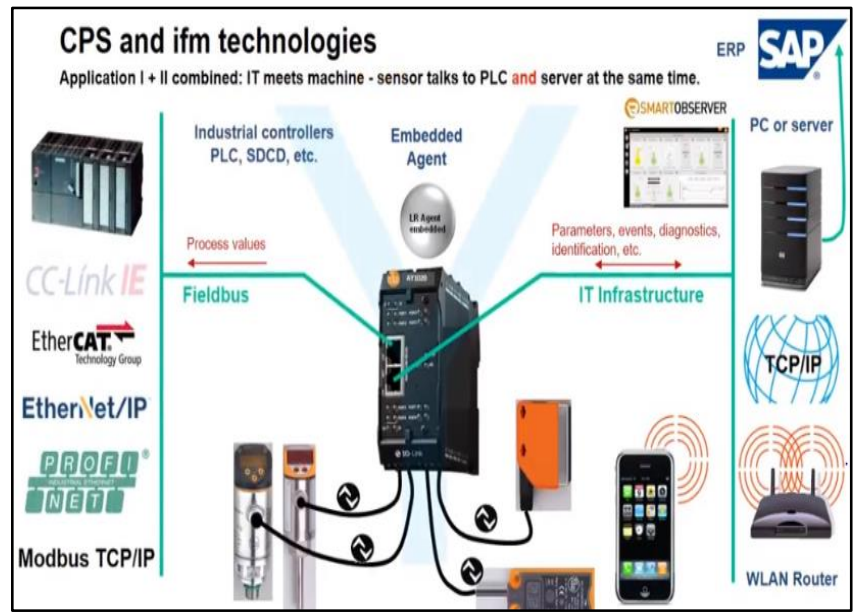

Fig. 3. Interface using AT1020 module

The second form of communication does not require specific hardware to perform the interface; however, it is not compatible with all sensors and PLCs. In this option, is used only one router to make the connection, via Ethernet, between IO-Link modules or a PLC. In the case of Siemens PLCs that were used in this project, TIA Portal ${ }^{\circledR}$ software (Fully Integrated Automation Portal) was used to search DBs (database) of PLC. In figure 4 there is an illustration of the second form, which was the one used in the project, due 
to the frequency limitations caused by encoders tube forming machine.

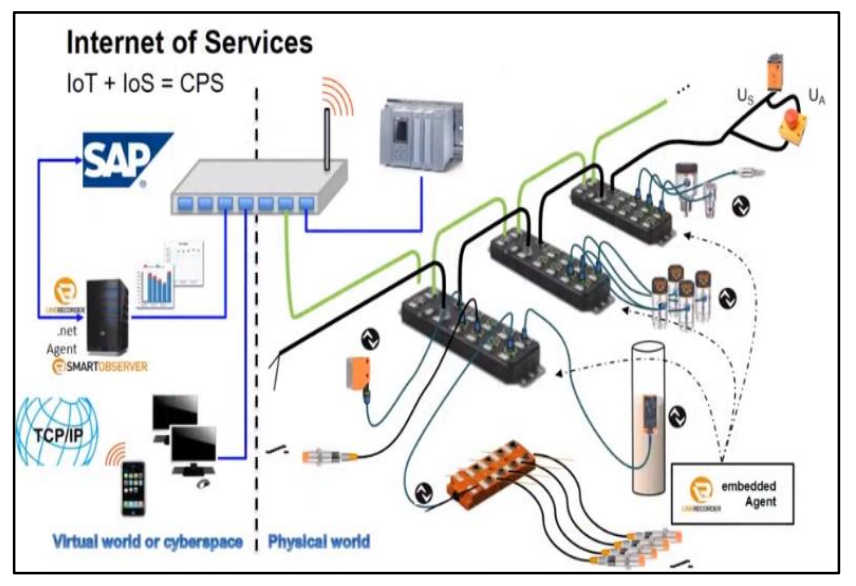

Fig. 4 - Interface using a router

\subsection{Software}

In addition to LineRecorder ${ }^{\circledR}$ software mentioned above, two other software were used to enable communication among SmartObserver ${ }^{\circledR}$, PLC and Tubing Machine Sensors, Microsoft SQL Server Express ${ }^{\circledR}$ and TIA Portal ${ }^{\circledR}$ V13.

Microsoft SQL Server Express ${ }^{\circledR}$ was used as the database software, since it supports remote connections. It is important to note that in this project a free version was used, with data storage limitations. However, with the expansion of the number of tube forming machines monitored by SmartObserver ${ }^{\circledR}$ in the plant, it will be necessary to acquire the complete software.

TIA Portal ${ }^{\circledR}$ V13, which was used to acquire PLC data, is a software that seeks to aid in increasing plant productivity through additional diagnostics and power management functions, while offers a greater flexibility in level of equipment management.

In TIA Portal ${ }^{\circledR}$, data acquisition is only possible if the user knows the $\mathrm{DB}$ and the slot where the information that will be monitored is being recorded. In this software, it is possible to configure, according to the need of the user, the frequency of data acquisition. It is worth mentioning that the higher the frequency, the greater the database required ${ }^{(5)}$.

\subsection{SmartObserver ${ }^{\circledR}$ Configuration}

SmartObserver ${ }^{\circledR}$ is the interaction environment between the user and the place where all necessary analyzes and follow-ups will be performed. In the software it is possible to assemble panels according to the user's need. Production can mount equipment speed panels, usage rate, nonconforming products, among others. Maintenance can mount an exclusive panel with alarms, parameter measurements and interruptions. SmartObserver ${ }^{\circledR}$ cockpit is user-friendly and can be configured by the end user easily. However, its configuration as users, alarm limit, insertion of variables is performed through the LineRecorder Configuration Manager ${ }^{\circledR}$ that is installed together with $\mathrm{LR}^{(5)}$.

Another type of configuration that will be available in the future is the sending of alarms, by machine time, for example, by email or SMS. In figure 5, it is possible to see an example of a mounted panel to monitor machine status, production speed and current parameters of machine's motors.

The panel presents information online and can be viewed directly from the manager's room, thus facilitating the monitoring of the machine.

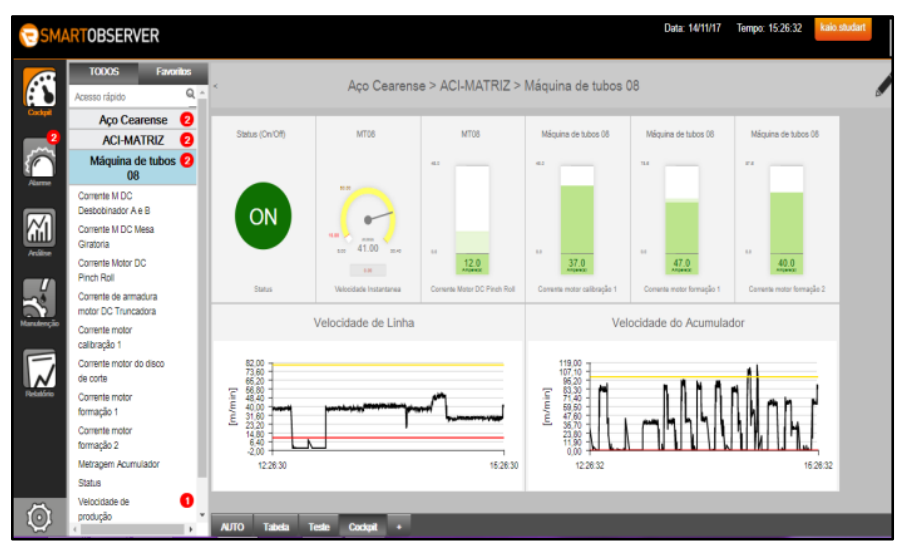

Fig. 5- Cockpit SMARTOBSERVER $®$

\section{Results}

The implementation of SmartObserver ${ }^{\circledR}$ was only carried out in Tubing Forming 08 (MT08), as this was a pilot project. In order to compare the productivity evolution of this machine with the rest of the plant it was used the average interruption (in minutes) per month and shift (AIMS) which is calculated as shown in equation 1, where NWS is the number of working shifts and NM the number of months in the period.

$$
A I M S=\frac{\text { Interruption }}{N W S \times N M}
$$

Using this indicator, it was possible to compare the productivity of MT08 with the rest of the factory.

It is noteworthy that the MT08 produces during 3 working shifts per day while the rest of the plant operates in 2 shifts what leads it to have naturally a longer interruption time when compared to only the average interruption time 
per month. The periods used for comparison were 2016 and 2017 (January to September) because SmartObserver ${ }^{\circledR}$ was implemented in January 2017.

During 2017, manual and automatic pointing were maintained for purpose of analyzing the percentage of divergence between the methods. As can be seen in Figure 6, the error between the methods during 2017 was $6 \%$ in 2017.

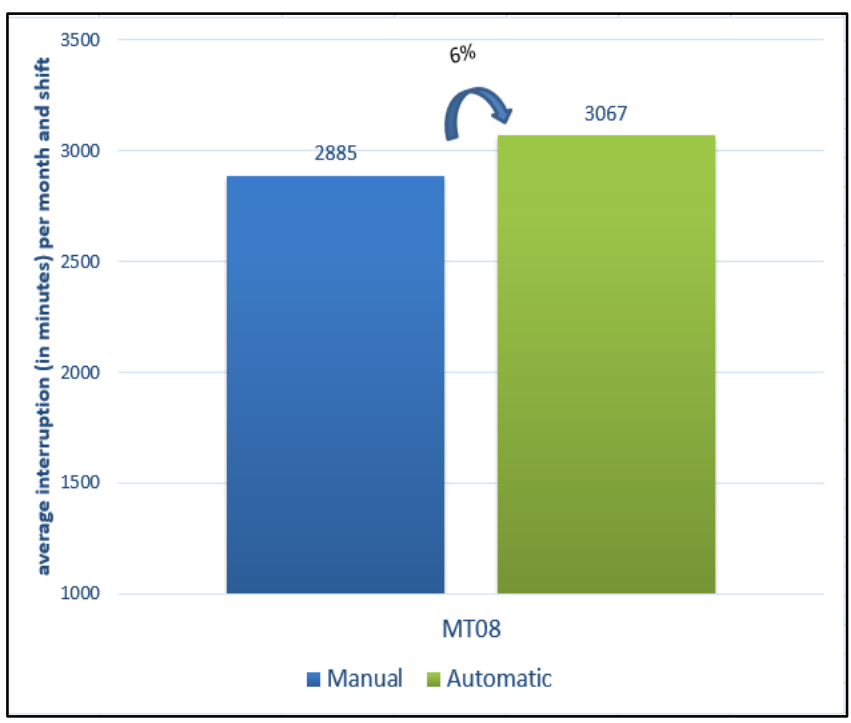

Fig. 6 - Comparison between two methods

To compare the evolution between the periods the manual database was used, since does not exist an automatic base of 2016

It is possible to see in figure 07 that in comparison with the period before SmartObserver ${ }^{\circledR}$ implantation it was achieved a reduction of $9 \%$ in the interruptions of MT08, while the rest of the plant had a certain stability with a $3 \%$ increase. This increase is mostly due to a $4 \%$ increase in production that was recorded in the same period of analysis.

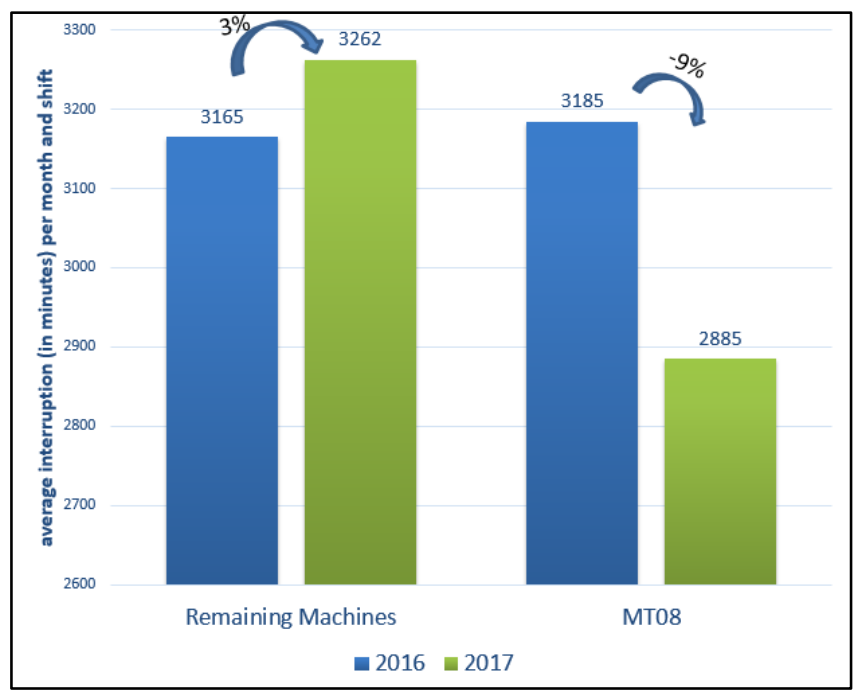

Fig. 7 - Evolution from 2016 to 2017
In Figure 8 we can see the evolution of MT08 by type of interruption.

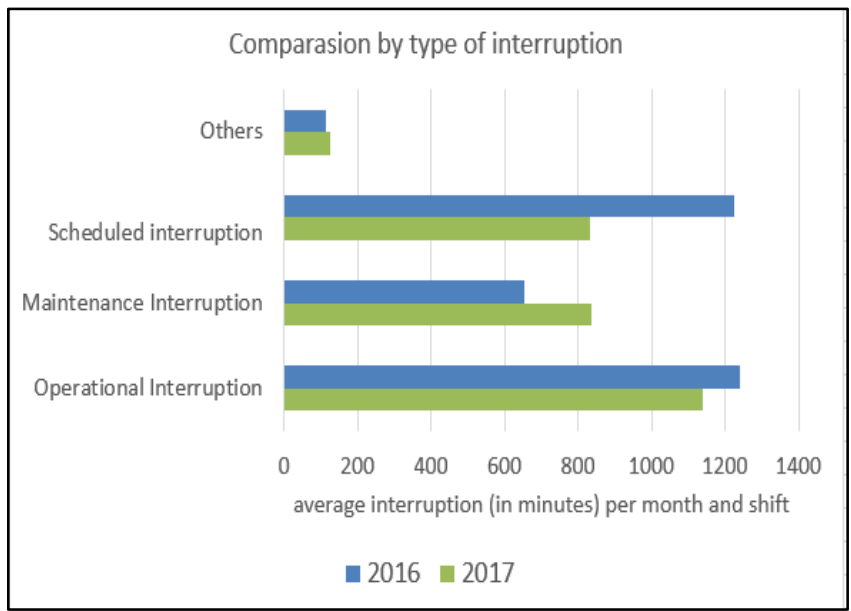

Fig. 8 - Comparison by type of interruption

During this work, it was possible to observe errors of manual notes when compared to the automatic note of SmartObserver ${ }^{\circledR}$ this fact contributed in an impressive way in the observation of the problems of scheduled stops like mealtime and machine setups. With more accurate data from SmartObserver ${ }^{\circledR}$ and the real-time observance of the machine by the managers, it was possible to carry out effective works to reduce this type of interruption.

In the interruptions of maintenance type, it was not possible to verify the indicator evolution. In the meantime, in 2017 there was an equipment reaching the end of its useful life that affected average 200 minutes per month. Removing the interruptions of this equipment, which was something punctual, an evolution would have been registered in the indicator. It is worth mentioning that the real-time monitoring of the currents of all the motors of the equipment allowed the maintenance team to act in a predictive way on the larger electric motor of the machine avoiding a great interruption in June 2017.

In the operational interruptions, which for the most part are of short duration, Smartobserver ${ }^{\circledR}$ contributed because the operator did not register the manual interruption for being of maximum 10 minutes. With the visualization of the small rhythm breaks imposed by these interruptions, a working group (PDCA-MASP) focused on reducting operational interruptions was implemented, which resulted in an $8 \%$ reduction in what is the main cause of interruptions in the tube forming machines.-

In total, the implementation of SmartObserver ${ }^{\circledR}$ assisted in the evolution of the interruption indicator of MT08 from 3185 minutes per month per turn to 2885 , generating a 
reduction of 300 minutes per month per shift. Thus the gain per month was 900 minutes. MT08 produces on average $44.68 \mathrm{~kg}$ per minute, leading to a production gain of more than 40.21 tons per month. The average selling price of the final material is $\mathrm{R} \$ 4,150.00$ per ton with a profit margin of $12 \%$. With this a final gain of $\mathrm{R} \$ 20,025$ per month was registered, which generates an annual gain of $\mathrm{R} \$ 240,000.00$.

\section{Conclusions}

Looking at the process, a breakthrough has occurred in the reliability and speed of data arrival. The rhythm notes of the machine were no longer manual and became automatic. Thus, the work to reduce losses was focused and based on the information obtained from the software, always analyzing the variables that caused the rhythm breaks and the reduction of the speed of the process.

For the maintenance industry, the reading of machine variables, such as the current of the electric motors, without the need of the inspector figure, accelerated the predictive maintenance process and made the system more reliable. The historical generated by the constant reading of the variables allowed the identification of anomalies that could lead to stops of the equipment and consequently production.

For the machine under study, the next step is to enable the sending of alarms to the managers, via SMS or e-mail, with information of great value to speed up even more the decision making.

SmartObserver ${ }^{\circledR}$ is a tool that is aligned with the concepts of Industry 4.0 in which practically real-time monitoring of the conditions of the tube forming machine has helped managers and supervisors to make assertive decisions that have led to the reduction of interruptions in a significant way.

The fact that SmartObserver ${ }^{\circledR}$ cockpit has a nice design and its access via the web has made the tool easy to disseminate among company managers. Another factor that helped in the acceptance of the software is its compatibility with the company's PLCs (Siemens), which are predominant in all equipment of the factory under study. Finally, it can be said that the good results presented and the good acceptance among the managers will allow the expansion of this project in the other equipment within the group.

\section{References}

(1) Gustavo Sevegnani, Adelmo Anselmo Martins (et al): "Monitoring System of Machine Stops in One
Machining Line - A Study of Case”, National Meeting of Production Engineering (ENEGEP),pp 2, 2010.

(2) Henning Kagermann, Wolfgang Wahlster, and Johannes Helbig: "Recommendations for implementing the strategic initiative INDUSTRIE 4.0", National Academy of Science and Engineering (ACATECH), pp. 12-25, 2013.

(3) IFM Electronic: " 8 - port IO-Link master module with LINERECORDER AGENT embedded", IFM article no. 78001437, pp 1-2, 2015.

(4) IFM Electronic: "The Software innovation: LineRecorder Agent”, pp 1-2, 2014.

(5) IFM Electronic: "Deployment Diagram Smartobserver",pp 1-42, 2016. 